\title{
Quality analysis of chest compression during cardiopulmonary resuscitation performed by firefighters with physical effort
}

\author{
Łukasz Dudziński', Marcin Glinka², Dominik Wysocki³, Piotr Leszczyński, Mariusz Panczyk5
}

\author{
'State Fire Service Lublin, Lublin, Poland \\ ${ }^{2}$ State Fire Service Warsaw, Warszawa, Poland \\ ${ }_{3}^{3}$ Provincial Headquarters of State Fire Service Lublin, Lublin, Poland \\ ${ }^{4}$ Institute of Health Sciences, Faculty of Medical and Health Sciences, Siedlce University of Natural Sciences and Humanities, Siedlce, Poland \\ ${ }^{5}$ Department of Education and Research in Health Sciences, Faculty of Health Sciences Medical University of Warsaw, Warszawa, Poland
}

\author{
Correspondence to: \\ Łukasz Dudziński, PhD, \\ State Fire Service Lublin \\ Szczerbowskiego 6, \\ 20-012 Lublin, Poland \\ phone: +48 815351320 , \\ e-mail: \\ lukasz_dudzinski@o2.pl \\ Copyright by the \\ Author(s), 2021 \\ Kardiol Pol. 2021; \\ 79 (6): 690-692; \\ DOI: $10.33963 /$ KP.15992 \\ Received: \\ January 11, 2021 \\ Revision accepted: \\ April 26, 2021 \\ Published online: \\ April 29, 2021
}

\section{INTRODUCTION}

The medical activities of firefighters in the State Fire Service (SFS) are based on 22 advanced first aid procedures (FAP). The procedures apply to both traumatic and non-traumatic health and life-threatening conditions $[1,2]$. The most demanding FAP procedures concern cardiopulmonary resuscitation (CPR) broken down by age groups of victims [3]. They are concerned with the management of cardiac arrest in adults, children, infants, and newborns $[4,5]$. The medical firefighter training system and the adult CPR procedure used in SFS are described in Supplementary material, Figure $S 1$.

Successful CPR management and the chance of a return to spontaneous circulation (ROSC) depend on various factors. One of them are correct chest compressions in line with the European Resuscitation Council (ERC) guidelines for basic life support (BLS). For an adult, effective action is obtained by compressing in the right place (center of the chest), at a rate of 100-120 per minute, to a depth of 5-6 cm, as well as correct relaxation $[6,7]$. Among the factors that influence the quality of compressions are practice, experience, mental state (stress load, acting in a public place), and physical conditions (weather conditions, overexertion). The study attempts to evaluate the effect of rescuer (firefighter) fatigue on the quality of adult chest compressions as an important part of CPR.

\section{METHODS}

The study involved compressing the Rescue Anne QCPR training manikin in a situation of physical and thermal stress of the rescuers. The fatigue effect was obtained by completing the test in a smoke chamber. Officers compressed the manikin's chest before the physical exercise for 2 minutes. Then the firefighters started the test in a smoke chamber (training path and chamber passage), where they obtained significant fatigue. For statistical analysis, the exercise time with the manikin (chest compressions) was presented in seconds (t. $\max =120$ seconds). The study was randomized, and participation depended on the schedule of tests in the smoke chamber.

The next sessions increasing the study population were scheduled for 2020, but the state of the SARS-CoV-2 epidemic made it impossible to increase the research sample. The study was approved by the Bioethics Committee at UPH Siedlce (No. 7/2019), and gained the consent of the Provincial Commander of the State Fire Service in Lublin. Each study participant gave their informed consent.

\section{Statistical analysis}

Statistical analysis is presented in Supplementary material.

Test parts to be assessed (parts I and III) Part I - 2-minute rest cycle of chest compressions - assessed in the study. A firefighter dressed in special clothing, no respiratory protection (RP) kit, no helmet. After completing the 2-minute compressions cycle, the study subject puts on the RP set and proceeds to part II.

Part II - physical effort - training path lasting 15 minutes with the RP worn but not 
connected, and the smoke chamber path with the RP on and connected. The passage time of the chamber path varies for each officer. The maximum passage time of the smoke chamber is limited by the air consumption in the cylinder. The smoke chamber path must be completed on the contents of one air cylinder. The average range of ventricular transit times is 6-10 minutes and depends on the individual characteristics of the exercising people. The exercise part was not assessed in the study, but it was necessary for the next part of the study.

Part III - a 2-minute cycle of chest compressions after exercise - assessed in the study. After leaving the smoke chamber, a firefighter approaches the CPR station, disconnects and takes off the RP kit, mask, and helmet, and starts compressing the manikin's chest. This part simulates the real conditions of rescue and firefighting operations (evacuating an unconscious person from the danger zone, finding no signs of circulation, starting CPR without being able to rest). Flow chart of the study stages is shown in Figure S2 in Supplementary material.

\section{RESULTS AND DISCUSSION}

In total, 72 firefighters at a mean (SD) age of 34.14 (6.67) participated in the study. The mean (SD) length of service was 9.6 years (4.27). The full-time task planned in the study (all 3 parts) was completed by 64 officers. Parts I and II were completed by all 72 officers. Eight firefighters did not complete part III. Five completed compressions on the manikin's chest after 85, 90, 94, 101, 105 seconds out of the scheduled 120 seconds, respectively, and three did not take this part declaring too much fatigue. The parameters important for the study are presented in Table 1. Additional data are described in Supplementary material in the Results section.

Due to the lack of publication and results of similar studies on the assessment of the quality of chest compressions before and after exercise among PSP officers, reference was made to other results assessing the quality of chest compressions, and the impact of resuscitation on prognosis, survival and health after an episode of sudden cardiac arrest (SCA).

Table 1. Descriptive statistics of quantitative variables

\begin{tabular}{|c|c|c|c|}
\hline Variable & Mean (SD) & W & $P$-value ${ }^{a}$ \\
\hline Age, years & $34.14(6.67)$ & 0.972 & 0.106 \\
\hline Length of service, years & $9.60(4.27)$ & 0.977 & 0.201 \\
\hline Depth of chest compressions at rest, $\mathrm{mm}$ & 47.85 (3.98) & 0.968 & 0.069 \\
\hline Variable & Median (IQR/2) & W & $P$-value ${ }^{a}$ \\
\hline Frequency of chest compressions at rest, comp./min & $110.75(5.88)$ & 0.961 & 0.025 \\
\hline Frequency of chest compressions after exercise, comp./min & $120.00(6.50)$ & 0.879 & 0.00001 \\
\hline Depth of chest compressions after exercise, $\mathrm{mm}$ & $47.00(5.00)$ & 0.914 & 0.00016 \\
\hline
\end{tabular}

aShapiro-Wilk test.

Abbreviations: IQR/2, Semi-interquartile range; SD, standard deviation; $W$, statistic value

\begin{tabular}{|c|c|c|c|c|c|c|c|}
\hline \multicolumn{2}{|c|}{ Function (n) } & \multicolumn{4}{|c|}{ Frequency of chest compressions, comp./min } & \multirow[t]{3}{*}{$\mathbf{t}^{\mathrm{a} / \mathbf{z}^{\mathrm{b}}}$} & \multirow[t]{3}{*}{$P$-value } \\
\hline & & \multicolumn{2}{|c|}{ At rest } & \multicolumn{2}{|c|}{ After exercise } & & \\
\hline & & M & SD & M & SD & & \\
\hline Commanders & (14) & 109.04 & 9.58 & 124.18 & 11.48 & 3.965 & $0.001^{\mathrm{a}}$ \\
\hline Fun & & Mdn & IQR/2 & Mdn & IQR/2 & & \\
\hline Rescuers & (41) & 112.25 & 4.75 & 120.50 & 6.13 & 3.139 & $0.002^{\mathrm{b}}$ \\
\hline Drivers & (9) & 108.00 & 3.75 & 109.75 & 10.75 & 1.013 & $0.311^{\mathrm{b}}$ \\
\hline All group & (64) & 110.75 & 5.69 & 120.00 & 6.56 & 3.354 & $0.001^{b}$ \\
\hline
\end{tabular}

a Matched-pairs t-test. ${ }^{b}$ Wilcoxon signed-rank test, t or z - statistic value.

Abbreviations: IQR/2, semi-interquartile range; $\mathrm{M}$, mean; $\mathrm{Mdn}$, median; $\mathrm{SD}$, standard deviation

\begin{tabular}{|c|c|c|c|c|c|c|c|}
\hline \multicolumn{2}{|c|}{ Function (n) } & \multicolumn{4}{|c|}{ Depth of chest compressions, mm } & \multirow[t]{3}{*}{$\mathbf{t}^{\mathrm{a} / \mathbf{z}^{\mathrm{b}}}$} & \multirow[t]{3}{*}{$P$-value } \\
\hline & & \multicolumn{2}{|c|}{ At rest } & \multicolumn{2}{|c|}{ After exercise } & & \\
\hline & & M & SD & $\mathbf{M}$ & SD & & \\
\hline Drivers & (9) & 47.46 & 3.64 & 47.42 & 3.65 & 0.312 & $0.760^{\mathrm{a}}$ \\
\hline Fur & & Mdn & IQR/2 & Mdn & IQR/2 & & \\
\hline Rescuers & $(41)$ & 48.50 & 1.75 & 44.00 & 5.00 & 3.813 & $<0.001^{\mathrm{b}}$ \\
\hline Commanders & (14) & 48.00 & 3.75 & 47.00 & 4.75 & 0.908 & $0.363^{b}$ \\
\hline All group & (64) & 48.00 & 2.50 & 47.00 & 4.63 & 3.476 & $0.001^{\mathrm{b}}$ \\
\hline
\end{tabular}

${ }^{a}$ Matched-pairs t-test. ${ }^{b}$ Wilcoxon signed-rank test, t or z — statistic value.

Abbreviations: IQR/2, semi-interquartile range; $\mathrm{M}$, mean; $\mathrm{Mdn}$, median; $\mathrm{SD}$, standard deviation 
Dąbrowski [8] in 2012 raised that the implementation of high-quality chest compressions without ventilation in the absence of equipment or safety. The 2015 CPR guidelines also addressed the issue of high-quality chest compressions as important for the further process of saving lives [9].

A similar topic of research was undertaken in 2014. In the cited work, the authors compared 3 methods of chest (device and non-device) compressions. Moreover, they described that the correct location of the chest compression point, pressure depth and frequency influenced the effectiveness of indirect heart massage and caused the correct compression of the heart muscle [10]. Similar results were presented in our study - firefighters' fatigue had a similar effect on lowering the quality of actions.

The authors also presented research on the quality of chest compression during CPR in the 2018 publication. A study comparing instrument and non-instrument operation had shown that the quality of manual chest compression performed during simulated adult resuscitation was lower than when using the chest compression system [11].

In another study from 2019, researchers cited data from the American Heart Association (AHA), according to which over 359000 out-of-hospital cardiac arrest (OHCA) incidents are registered in the United States every year. The update of the guidelines for cardiopulmonary resuscitation, taking place every few years, on the basis of the latest scientific reports, leads to an increase in patient survival. The quality of life after cardiac arrest is closely related to careful and effective CPR [12].

Chomoncik [13] presents that good knowledge of rescue procedures and continuous training have an impact on the quality and speed of advanced first aid activities, also during CPR.

In the 2018 analysis, Iskrzycki et al. [14] demonstrated that the use of a real-time visual external feedback device (CPRMeter) significantly improved the quality of chest compressions in rescuers with little experience. Comparing the conclusions obtained by the authors of the study to the own results, it can be assumed that the use of real-time CPR quality monitoring devices may have a beneficial effect not only in the case of inexperienced but also tired rescuers.

\section{CONCLUSIONS}

Rescuer fatigue has a statistically significant impact on the frequency and depth of chest compressions during CPR. Consider implementing a cyclical evaluation of resuscitation activities in the fire service as part of professional development. CRP results after physical effort suggest changing rescuers more frequently than every 2 minutes.

\section{Supplementary material}

Supplementary material is available at https://journals. viamedica.pl/kardiologia_polska.

\section{Article information}

Conflict of interest: None declared.

Open access: This article is available in open access under Creative Common Attribution-Non-Commercial-No Derivatives 4.0 International (CC BY-NC-ND 4.0) license, allowing to download articles and share them with others as long as they credit the authors and the publisher, but without permission to change them in any way or use them commercially. For commercial use, please contact the journal office at kardiologiapolska@ptkardio.pl.

How to cite: Dudziński Ł, Glinka M, Wysocki D, et al. Quality analysis of chest compression during cardiopulmonary resuscitation performed by firefighters with physical effort. Kardiol Pol. 2021; 79(6): 690-692, doi: 10.33963/KP.15992.

\section{REFERENCES}

1. Zając K, Važanić D. Patient in hypothermia - diagnostic and treatment problems in fire department. Crit Care Innov. 2018; 1: 34-36.

2. Sawicki A, Chrościcki D. Evaluation of firefighters' knowledge about medical procedures. Crit Care Innov. 2019; 2(3): 27-36.

3. Wiszniewski R. Gorgone Ch. Characteristics of medical procedures performed by firefighters. Crit Care Innov. 2019; 2(4): 17-24, doi: 10.32114/CCI.2019.2.4.17.24.

4. Tomaszewski P, Leszczyński PK. The role of the Volunteer Fire Service during interventions in rural agglomeration. Crit Care Innov. 2020; 3(1): 24-32, indexed in Pubmed: 10.32114/CCl.2020.3.1.24.32.

5. Principles of the organization of medical rescue in the National Fire and Rescue System. General Headquarters of the State Fire Service. https://www.gov.pl/web/kgpsp/wykaz-wazniejszych-zasad-obowiazujacych-w-ksrg (September 1, 2019).

6. Act on the State Emergency Medical Services of September 8, $2006 \mathrm{r}$. (Dz. U. Nr 191, poz.1410). https://isap.sejm.gov.pl/isap.nsf/DocDetails. xsp?id=WDU20061911410 (September 1, 2019).

7. Ma MHM, Chiang WC, Ko PCl, et al. A randomized trial of compression first or analyze first strategies in patients with out-of-hospital cardiac arrest: results from an Asian community. Resuscitation. 2012; 83(7): 806-812, doi: 10.1016/j.resuscitation.2012.01.009.

8. Dąbrowski M, Dąbrowska A, Sip M, et al. Researching the knowledge of basic resuscitation issues in SFS rescuers, medical students and interns. Nowiny Lek. 2012; 81: 647-652.

9. European resuscitation council guidelines 15.10 .2015 (summary of key changes). https://www.prc.krakow.pl/wytyczne.html (September 1,2019).

10. Szarpak $Ł$, Madziała M. How to increase the effectiveness of indirect heart massage? . Fire Rev. Rescue and civil protection. 2014; 9: 36-38.

11. Majer J, Smereka J, Ladny JR, et al. Quality of chest compression in physician-led CPR: do we need mechanical chest compression? Multicentre, randomized, crossover study. Adv Med Sci. 2018; 31: 314-321.

12. Głowacki Ł, Stasiowski M, Możdżyński B, et al. Evaluation of treatment results and selected prognostic factors in patients treated in the intensive care unit in 2015 after an incident of sudden cardiac arrest with return to spontaneous heart rate - preliminary report. Ann Acad Med. 2019; 73: 8-18.

13. ChomoncikM. Emergency Medical Services in the National Fire and Rescue System part I. Safety Fire Technol. 2013; 29: 131-152.

14. Iskrzycki L, Smereka J, Rodriguez-Nunez A, et al. The impact of the use of a CPRMeter monitor on quality of chest compressions: a prospective randomised trial, cross-simulation. Kardiol Pol. 2018; 76(3): 574-579, doi: 10.5603/KP.a2017.0255, indexed in Pubmed: 29297195. 